\title{
Omics in Myopia
}

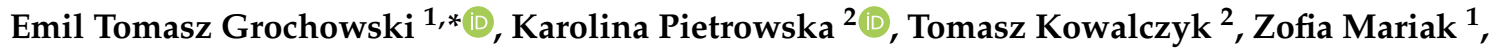 Adam Kretowski ${ }^{2,3}$, Michal Ciborowski ${ }^{2, *(1)}$ and Diana Anna Dmuchowska $1, *$ (D)}

1 Department of Ophthalmology, Medical University of Bialystok, M. Sklodowskiej Curie 24a, 15-276 Bialystok, Poland; mariakzo@umb.edu.pl

2 Clinical Research Centre, Medical University of Bialystok, M. Sklodowskiej Curie 24a, 15-276 Bialystok, Poland; kpietrowska89@gmail.com (K.P.); tomasz.kowalczyk000@gmail.com (T.K.); adam.kretowski@umb.edu.pl (A.K.)

3 Department of Endocrinology, Diabetology and Internal Medicine, Medical University of Bialystok, M. Sklodowskiej Curie 24a, 15-276 Bialystok, Poland

* Correspondence: emil.grochowski@umb.edu.pl (E.T.G.); michal.ciborowski@umb.edu.pl (M.C.); diana.dmuchowska@umb.edu.pl (D.A.D.)

Received: 8 October 2020; Accepted: 25 October 2020; Published: 28 October 2020

\begin{abstract}
Myopia is a globally emerging issue, with multiple medical and socio-economic burdens and no well-established causal treatment thus far. A better insight into altered biochemical pathways and underlying pathogenesis might facilitate early diagnosis and treatment of myopia, ultimately leading to the development of more effective preventive and therapeutic measures. In this review, we summarize current data about the metabolomics and proteomics of myopia in humans and present various experimental approaches and animal models, along with their strengths and weaknesses. We also discuss the potential applicability of these findings to medical practice and suggest directions for future research.
\end{abstract}

Keywords: myopia; metabolomics; proteomics; ocular biomarkers; mass spectrometry; liquid chromatography; gas chromatography; capillary electrophoresis

\section{Introduction}

Myopia is a condition in which the spherical equivalent objective refractive error in either eye decreases to $\leq-0.50$ diopter $(-0.50 \mathrm{D})$, whereas high myopia $(\mathrm{HM})$ is defined as the spherical equivalent objective refractive error in either eye $\leq-5.0 \mathrm{D}$ (according to WHO) or $\leq-6.0 \mathrm{D}$ (according to other sources). HM is associated with a significant axial elongation of the eye, with $>26.0$ or $26.5 \mathrm{~mm}$ being the most common threshold. HM accompanied by sight-threatening macular pathologies, such as choroidal neovascularization, chorioretinal atrophy (diffuse or more severe) [1] or Fuch's spot, can be classified as pathological myopia (PM) [2]. Myopia, especially HM, is associated with increased risk of non-macular conditions, such as rhegmatogenous retinal detachment (RRD), open-angle or pigmentary glaucoma, earlier cataract development and topical steroid hypersensitivity.

An increase in the prevalence of myopia has been observed globally, especially in East Asia, where this condition is found in up to $90 \%$ of school-leavers [3]. A plethora of factors, including ethnic/genetic susceptibility, environmental congestion, early education, near distance-related activities and reduced time outdoors, are suspected to increase the risk of myopia development [4]. The incidence of myopia varies significantly between populations, age groups and even people with various educational levels and has been steadily increasing over the last few decades. By 2050, the numbers of patients with myopia and HM are projected to reach 5 billion and 1 billion, respectively, making conditions from this spectrum a global pandemic [5]. 
Although myopia has been studied for decades, novel research methods may provide a better insight into the pathogenesis of this condition, which might eventually stimulate progress in its prevention and treatment. Progress in analytical methods and continuous improvement of computational capabilities allowed for the development of omics techniques. The use of the omics allows for a holistic approach to myopia pathogenesis. Proteomics and metabolomics are the last two components in the omics cascade, aimed at a global measurement of proteins and metabolites, respectively. Mass spectrometry (MS) is commonly applied in both approaches, facilitating detection of thousands of molecules in a small volume of biological material, which may lead to a better understanding of human physiology in health and disease [6]. Identification of potential novel biomarkers and disturbed metabolic pathways may contribute to a better understanding of myopia pathophysiology and may indicate novel therapeutic targets. It would also facilitate stratification of patients according to their risk profiles and earlier diagnosis. This could have direct translation into prognosis. Especially taking into account the fact that choroid neovascularization is treatable with anti-VEGF injections, and can have dramatic consequences when left untreated, the frequency of follow-up visits could be adjusted accordingly. As another example, one may speculate that timely identification of patients with high risk for rhegmatogenous retinal detachment may encourage 360-degree laser cerclage, which is not a standard procedure. In general, this could direct the treatment of myopia towards individualized medicine.

\section{Materials and Methods}

The PubMed database was searched for articles containing "myopia metabolomic" and "myopia proteomic*" phrases, indexed until 12 September 2020. Review articles, original papers missing detailed information about sample treatment and analytical conditions, as well as those not related to myopia and omics (e.g., restricted only to ELISA), were not included in the review.

Eventually, after detailed inspection and removal of duplicates, 34 original articles were found eligible for the review.

MetaboAnalyst 4.0 software (www.metaboanalyst.ca) was used for pathway analysis.

\section{Results}

Twenty-six proteomics-based articles, including four pure data articles, are summarized in Table 1. Seven of these studies included human patients, and nineteen were conducted in various animal models. Most of them were untargeted analyses of various samples, vitreous humor, retina and aqueous humor being the most common. Some of these studies aimed at the creation of proteome libraries, while others compared different animal models. Human studies focused on proteome comparison of myopic eyes to either emmetropic eyes or with concomitant pathologies. Orthokeratology lens and atropine as treatment for myopia were also assessed from the proteomic point of view.

Eight metabolomics-based studies, most of them untargeted, among them seven involving human patients and only one carried in guinea pigs, are summarized in Table 2. In contrast to proteomic studies, the metabolomic studies focused mainly on serum analyses. From strictly eye-related samples, the aqueous humor was analyzed. 
Table 1. Summary of published studies using proteomic analysis in myopia patients/animal models.

\begin{tabular}{|c|c|c|c|c|c|c|}
\hline $\begin{array}{l}\text { Type of Analytical } \\
\text { Method }\end{array}$ & Type of Analysis & Type of Sample & Organism & $\begin{array}{l}\text { Name of the Protein and/or } \\
\text { Protein-Encoding Gene }\end{array}$ & Scientific Aspects & Ref. \\
\hline SDS-PAGE MALDI TOF & untargeted & corneal epithelium & human & S100A4, KRT3, GSN, ENO1 & $\begin{array}{l}\text { comparison of patients with } \\
\text { keratoconus vs. myopic patients as } \\
\text { the controls }\end{array}$ & [7] \\
\hline SWATH-MS & untargeted & vitreous humor & $\begin{array}{l}\text { white } \\
\text { Leghorn } \\
\text { chicks }\end{array}$ & - & $\begin{array}{l}\text { creation of a proteome library in } \\
\text { emmetropization }\end{array}$ & [8] \\
\hline SWATH-MS & untargeted & tears & human & - & $\begin{array}{l}\text { creation of a proteome library in } \\
\text { patients wearing orthokeratology } \\
\text { lenses as treatment of myopia }\end{array}$ & [9] \\
\hline Label-free LC-MS & untargeted & vitreous humor & human & PTGDS, GPX3 & $\begin{array}{l}\text { identification of expressed proteins } \\
\text { in patients with pathological myopia } \\
\text { and controls }\end{array}$ & [10] \\
\hline 2D-PAGE MALDI TOF & untargeted & sclera & $\begin{array}{l}\text { shrews } \\
\text { (Tupaia } \\
\text { belangeri) }\end{array}$ & $\begin{array}{l}\text { pigment epithelium-derived } \\
\text { factor, procollagen I } \alpha 1 \text {, } \\
\text { procollagen I } \alpha 2, \\
\text { thrombospondin I, } \\
\text { glucose-regulated protein }\end{array}$ & $\begin{array}{l}\text { analysis of differences in the } \\
\text { development of lens-induced } \\
\text { myopia and recovery from } \\
\text { this condition }\end{array}$ & [11] \\
\hline SWATH-MS & untargeted & cornea & $\begin{array}{l}\text { white } \\
\text { Leghorn } \\
\text { chicks }\end{array}$ & - & $\begin{array}{l}\text { creation of a corneal proteome } \\
\text { library in high myopia }\end{array}$ & [12] \\
\hline 2D-PAGE MALDI TOF & untargeted & retina & mouse & Cryga, Cryba2, Cryba1 & $\begin{array}{c}\text { analysis of differences after exposure } \\
\text { to various light conditions }\end{array}$ & [13] \\
\hline 2D-PAGE LC-MS & untargeted & retina, RPE, choroid & $\begin{array}{l}\text { tilapia } \\
\text { (Oreochromis } \\
\text { niloticus) }\end{array}$ & annexin A5, gelsolin, TCP-1 & $\begin{array}{l}\text { analysis of differences in the protein } \\
\text { profiles found in induced myopia }\end{array}$ & [14] \\
\hline Label-free LC-MS & untargeted & vitreous humor & mouse & over 30 differentiating proteins & $\begin{array}{l}\text { analysis of high myopia profiles with } \\
\text { the low-density lipoprotein } \\
\text { receptor-related protein } 2\end{array}$ & [15] \\
\hline 2D-PAGE MALDI-TOF & untargeted & retina & $\begin{array}{l}\text { white } \\
\text { Leghorn } \\
\text { chicks }\end{array}$ & $\begin{array}{c}\text { VIL1, DPYSL2, SARS, } \\
\text { SEPTIN2, PGAM1 } \\
\text { tubulin } \alpha, \text { tubulin } \beta 2, \text { tubulin } \\
\alpha \text {-chain, } \beta \text {-tubulin }\end{array}$ & $\begin{array}{l}\text { analysis of differences in retinal } \\
\text { proteins from lens-induced myopic } \\
\text { chicks and controls }\end{array}$ & [16] \\
\hline
\end{tabular}


Table 1. Cont

\begin{tabular}{|c|c|c|c|c|c|c|}
\hline $\begin{array}{l}\text { Type of Analytical } \\
\text { Method }\end{array}$ & Type of Analysis & Type of Sample & Organism & $\begin{array}{l}\text { Name of the Protein and/or } \\
\text { Protein-Encoding Gene }\end{array}$ & Scientific Aspects & Ref. \\
\hline $\begin{array}{l}\text { ICPL LC-MS, } \\
\text { MRM LC-MS }\end{array}$ & $\begin{array}{l}\text { untargeted, } \\
\text { targeted }\end{array}$ & retina & $\begin{array}{l}\text { white } \\
\text { Leghorn } \\
\text { chicks } \\
\text { white }\end{array}$ & VIM, APOA1, GSTM2 & $\begin{array}{l}\text { identification of proteins in myopic } \\
\text { chicks and their association with } \\
\text { excessive eye elongation } \\
\text { identification of proteins }\end{array}$ & [17] \\
\hline ICPL LC-MS & untargeted & vitreous humor & $\begin{array}{l}\text { Leghorn } \\
\text { chicks }\end{array}$ & APOA1, TF, purpurin & $\begin{array}{l}\text { differentiating myopia } \\
\text { from hyperopia }\end{array}$ & [18] \\
\hline iTRAQ LC-MS & untargeted & aqueous humor & human & $\begin{array}{c}\text { ATP8A1, KRT2, KRT10, } \\
\text { CRYAA, CRYBA4, CRYAA, } \\
\text { CRYBB1, CRYBB2, CRYBA1, } \\
\text { KRT6B, KRT6A, KRT14, KRT16 }\end{array}$ & $\begin{array}{l}\text { comparison of protein profiles in } \\
\text { patients undergoing cataract surgery } \\
\text { with concomitant myopia, glaucoma, } \\
\text { or diabetes and controls }\end{array}$ & [19] \\
\hline iTRAQ LC-MS & untargeted & retina & mouse & over 25 differentiating proteins & $\begin{array}{l}\text { analysis of atropine effect on retina } \\
\text { proteome in myopic mice }\end{array}$ & [20] \\
\hline Label-free LC-MS & untargeted & retina & chicks & $\begin{array}{l}\text { analysis of a biochemical } \\
\text { pathway }\end{array}$ & $\begin{array}{l}\text { identification of pathways involved } \\
\text { in myopia and hyperopia } \\
\text { analysis of changes in protein }\end{array}$ & {$[21]$} \\
\hline 2D-PAGE MALDI-TOF & untargeted & sclera & guinea pig & Cryab, CryaA & $\begin{array}{l}\text { profiles during the development of } \\
\text { form-deprivation myopia and } \\
\text { recovery from this condition } \\
\text { analysis of changes in the protein }\end{array}$ & [22] \\
\hline 2D-PAGE LC-MS & untargeted & sclera & tree shrew & over 50 differentiating proteins & $\begin{array}{l}\text { profiles of lens-induced myopia and } \\
\text { recovery from this condition }\end{array}$ & [23] \\
\hline SWATH, MRM-MS & untargeted, targeted & retina & guinea pigs & - & $\begin{array}{l}\text { creation of a proteome library } \\
\text { in emmetropization }\end{array}$ & {$[24]$} \\
\hline 2D-PAGE MALDI-TOF & untargeted & $\begin{array}{l}\text { retina and fibrous } \\
\text { sclera }\end{array}$ & chicks & $\begin{array}{c}\text { APOA1, CRMP-62, CKB, } \\
\text { ENO2, tubulin } \alpha-1 \text { chain, VIM }\end{array}$ & study of emmetropization & [25] \\
\hline iTRAQ LC-MS & untargeted & aqueous humor & human & $\begin{array}{c}\text { over } 200 \text { differentiating } \\
\text { proteins }\end{array}$ & $\begin{array}{l}\text { identification of proteins } \\
\text { contributing to the development of } \\
\text { cataract in myopic patients }\end{array}$ & [26] \\
\hline Label-free LC-MS & untargeted & $\begin{array}{l}\text { retina, retinal } \\
\text { pigment epithelium }\end{array}$ & $\begin{array}{l}\text { chicks } \\
\text { (White } \\
\text { Leghorn/New } \\
\text { Hampshire) }\end{array}$ & over 65 differentiating proteins & $\begin{array}{l}\text { analysis of proteomic responses to } \\
\text { early optical defocus in relation to } \\
\text { transcriptome-level changes }\end{array}$ & [27] \\
\hline
\end{tabular}


Table 1. Cont

\begin{tabular}{|c|c|c|c|c|c|c|}
\hline $\begin{array}{l}\text { Type of Analytical } \\
\text { Method }\end{array}$ & Type of Analysis & Type of Sample & Organism & $\begin{array}{l}\text { Name of the Protein and/or } \\
\text { Protein-Encoding Gene }\end{array}$ & Scientific Aspects & Ref. \\
\hline 2D-PAGE MALDI-TOF & untargeted & aqueous humor & human & ALB, TTR, GC & $\begin{array}{l}\text { comparison of the proteome in high } \\
\text { myopia patients and controls }\end{array}$ & {$[28]$} \\
\hline 2D-PAGE MALDI-TOF & untargeted & retina & guinea pig & $\begin{array}{c}\text { ACTB, MDH1, Rab-11B, PKM2, } \\
\text { ACP1 }\end{array}$ & $\begin{array}{c}\text { analysis of differential protein } \\
\text { expression in response to } \\
\text { lens-induced myopia }\end{array}$ & [29] \\
\hline SWATH-MS, MRM-MS & $\begin{array}{l}\text { untargeted } \\
\text { targeted }\end{array}$ & retina & guinea pig & - & $\begin{array}{l}\text { creation of a spectral library of } \\
\text { protein profile changes during } \\
\text { emmetropization }\end{array}$ & {$[30]$} \\
\hline 2D-PAGE LC-MS & untargeted & retina & chick & $\begin{array}{l}\text { ARR3, Rab-11B, PSMD14, } \\
\beta \text {-tubulin, PRDX6, UCH-L1 }\end{array}$ & $\begin{array}{l}\text { proteome study during early } \\
\text { recovery from lens-induced myopia }\end{array}$ & [31] \\
\hline Label-free LC-MS & untargeted & vitreous humor & human & over 50 differentiating proteins & $\begin{array}{l}\text { analysis of protein expression } \\
\text { profiles in vitreous humor from } \\
\text { patients with pathologic myopic } \\
\text { retinoschisis with/without } \\
\text { intravitreal antivascular endothelial } \\
\text { growth factor therapy }\end{array}$ & {$[32]$} \\
\hline
\end{tabular}


Table 2. Summary of published studies using metabolomic analysis in myopia patients/animal models.

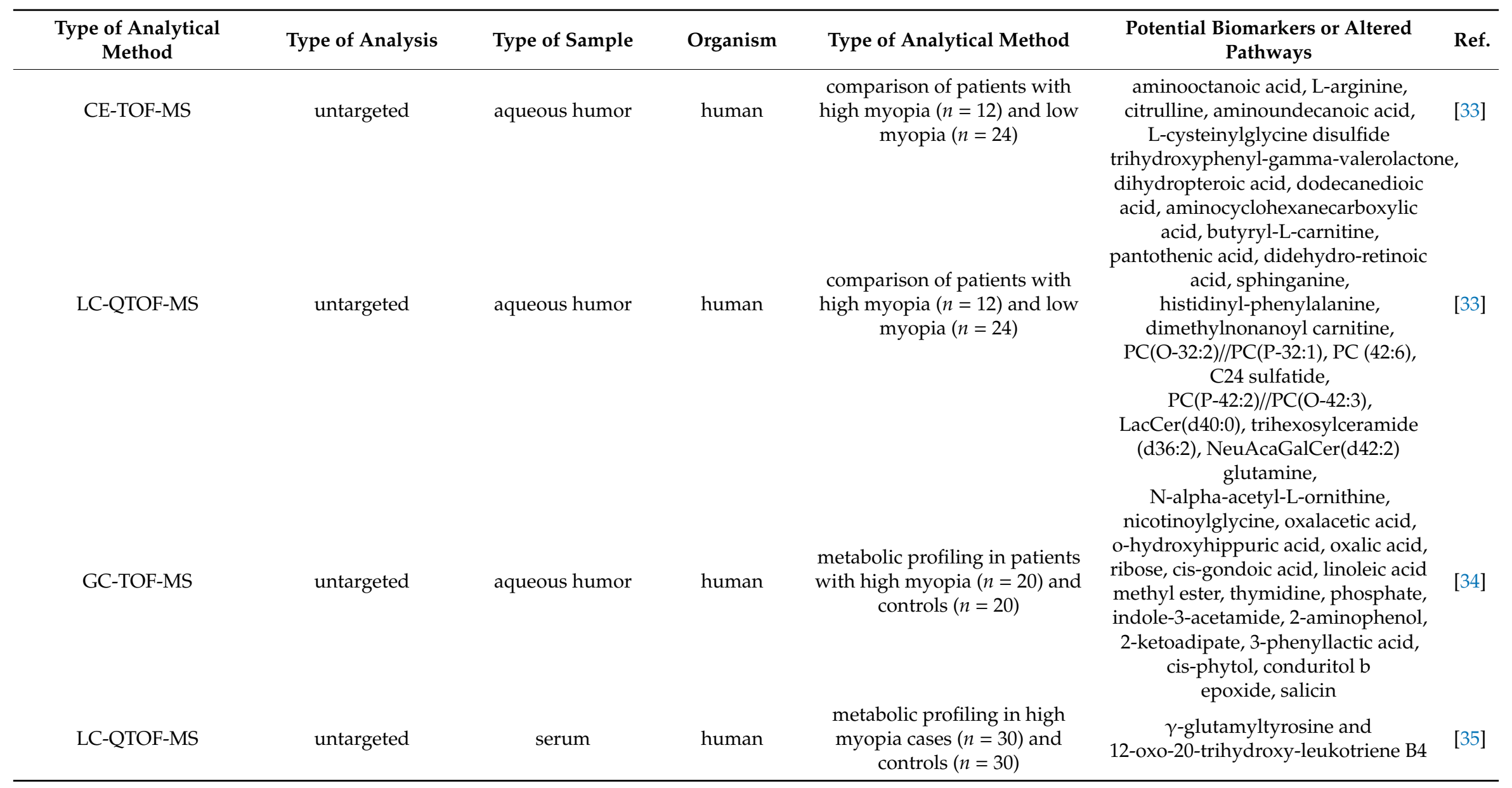


Table 2. Cont

\begin{tabular}{|c|c|c|c|c|c|c|}
\hline $\begin{array}{l}\text { Type of Analytical } \\
\text { Method }\end{array}$ & Type of Analysis & Type of Sample & Organism & Type of Analytical Method & $\begin{array}{c}\text { Potential Biomarkers or Altered } \\
\text { Pathways }\end{array}$ & Ref. \\
\hline UHPLC-MS & untargeted & serum & human & $\begin{array}{l}\text { metabolomics profiling in } \\
\text { myopia cases }(n=108) \text { and } \\
\text { controls }(n=103)\end{array}$ & $\begin{array}{l}\text { steroid biosynthesis, lysine } \\
\text { degradation, arginine and proline } \\
\text { metabolism, glycerolipid } \\
\text { metabolism, glycerophospholipid } \\
\text { metabolism, arachidonic acid } \\
\text { metabolism, linoleic } \\
\text { acid metabolism, } \\
\text { sphingolipid metabolism }\end{array}$ & [36] \\
\hline UHPLC-MS & untargeted & serum & human & $\begin{array}{l}\text { lipid profiling in myopia cases } \\
(n=108) \text { and controls }(n=103)\end{array}$ & $\begin{array}{l}\text { steroid biosynthesis, lysine } \\
\text { degradation, glycerolipid } \\
\text { metabolism, glycerophospholipid } \\
\text { metabolism, arachidonic acid } \\
\text { metabolism, linoleic acid } \\
\text { metabolism, alpha-linolenic } \\
\text { acid metabolism, } \\
\text { sphingolipid metabolism }\end{array}$ & [36] \\
\hline GC-TOF-MS & untargeted & serum & human & $\begin{array}{l}\text { metabolomic analysis of } \\
\text { patients with high myopia }(n= \\
40) \text { and low myopia }(n=40)\end{array}$ & $\begin{array}{l}\text { alanine, mannose, itaconic acid, } \\
\text { aconitic acid, O-acetylserine, } \\
\text { phthalic acid, abietic acid, salicin, } \\
\text { citric acid, aminomalonic acid, } \\
\text { palmitoleic acid, conduritol b } \\
\text { epoxide, shikimic acid, } \\
\text { 4-hydroxyphenylacetic acid, } \\
\text { hesperitin, anandamide, oxalacetic } \\
\text { acid, pimelic acid, 2-ketoadipate, } \\
\text { N-ethylmaleamic acid }\end{array}$ & [37] \\
\hline GC-TOF-MS & untargeted & serum & human & $\begin{array}{c}\text { metabolic profiling in patients } \\
\text { with pathological myopia }(n= \\
\text { 57) and controls }(n=81)\end{array}$ & $\begin{array}{c}\text { hypoxanthine, } \\
\text { L-2-amino-3-(1-pyrazolyl)propanoic } \\
\text { acid, linoleic acid, maleic } \\
\text { acid, ribonolactone }\end{array}$ & [38] \\
\hline
\end{tabular}


Table 2. Cont.

\begin{tabular}{|c|c|c|c|c|c|c|}
\hline $\begin{array}{l}\text { Type of Analytical } \\
\text { Method }\end{array}$ & Type of Analysis & Type of Sample & Organism & Type of Analytical Method & $\begin{array}{l}\text { Potential Biomarkers or Altered } \\
\text { Pathways }\end{array}$ & Ref. \\
\hline LC-On-Line SPE-MS/MS & targeted & serum & human & $\begin{array}{c}\text { myopia patients }(n=25) \text { and } \\
\text { controls }(n=29) \\
\text { at the baseline and after } \\
\text { 18-month follow-up ( } 22 \\
\text { patients and } 23 \text { controls) }\end{array}$ & melatonin, dopamine & [39] \\
\hline GC-TOF-MS & untargeted & retina & guinea pig & $\begin{array}{l}\text { time-dependent } \\
\text { form-deprivation myopia, } \mathrm{T}= \\
3 \text { days, } 12 \text { cases and } 5 \text { controls }\end{array}$ & $\begin{array}{l}\text { mannose, urea, glucose, arabinose, } \\
\text { tyrosine, glutamic acid, threonine, } \\
\text { valine, isoleucine, malic acid, alanine }\end{array}$ & [40] \\
\hline GC-TOF-MS & untargeted & retina & guinea pig & $\begin{array}{l}\text { time-dependent } \\
\text { form-deprivation myopia, } \mathrm{T}= \\
2 \text { weeks, } 12 \text { cases and } 6 \text { controls }\end{array}$ & $\begin{array}{l}\text { threonine, valine, isoleucine, malic } \\
\text { acid, alanine, arachidic acid (20:0), } \\
\text { octadecenoic acid (18:1), } \\
\text { octadecanoic acid (18:0), arachidonic } \\
\text { acid (20:4), cholesterol, } \\
\text { ethanolamine, hexadecanoic acid } \\
(16: 0), \text { tetradecanoic acid }(14: 0), \\
\text { octadecadienoic acid (18:2), } \\
\text { 2-ketoglutaric acid, GABA }\end{array}$ & [40] \\
\hline
\end{tabular}

Numbers in brackets are the numbers of patients included in the research. 
Inter-study pathway analysis was carried out separately for human serum and aqueous humor (AH) using MetaboAnalyst 4.0 software, as shown in Figure 1.

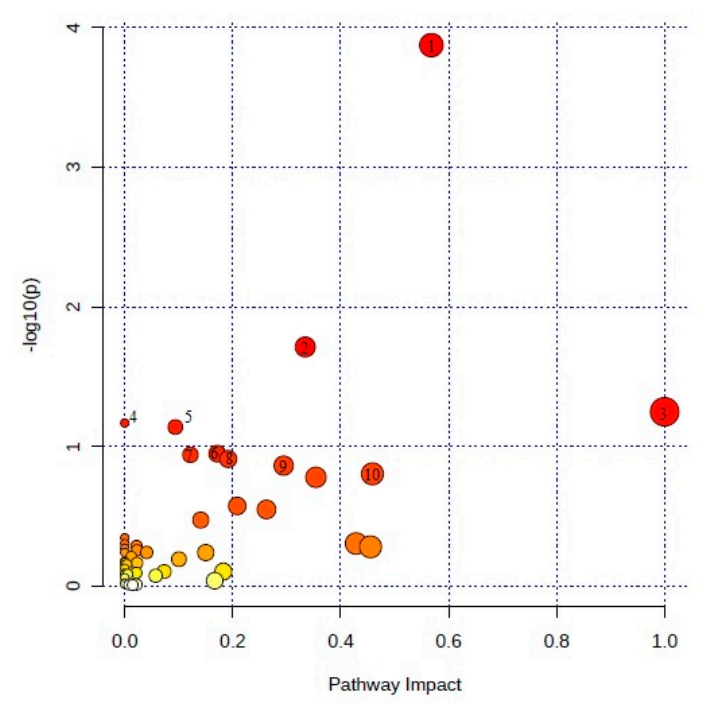

(a)

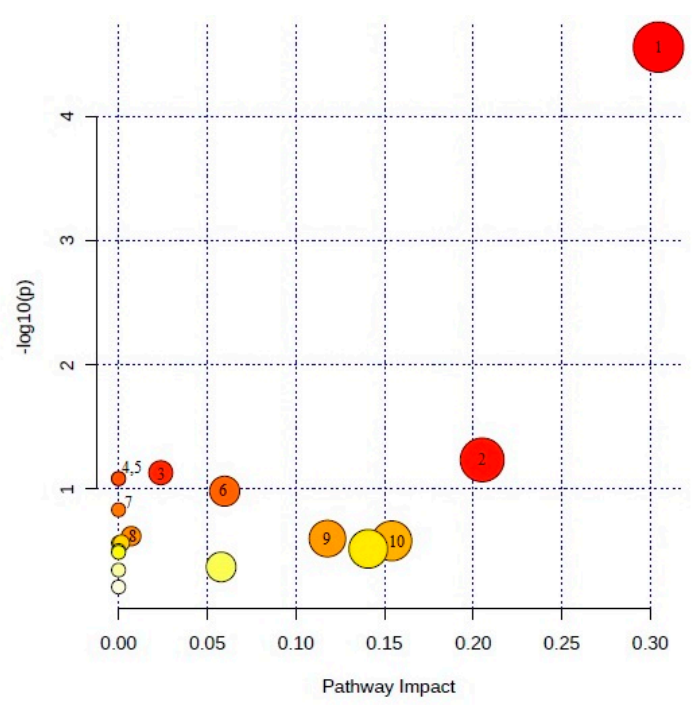

(b)

Figure 1. Metabolic pathway analysis performed for significant metabolites reported in human serum (a) and aqueous humor (AH) (b) samples. Metabolic pathway analysis was carried out with MetaboAnalyst 4.0 software. Ten most significant pathways identified for the serum samples: 1. sphingolipid metabolism, 2. citrate cycle (TCA cycle), 3. linoleic acid metabolism, 4. biosynthesis of unsaturated fatty acids, 5. alanine, aspartate and glutamate metabolism, 6. tryptophan metabolism, 7. glyoxylate and dicarboxylate metabolism, 8. tyrosine metabolism, 9. glycerolipid metabolism, and 10. retinol metabolism. Ten most significant pathways identified for the AH samples: 1. arginine biosynthesis, 2. alanine, aspartate and glutamate metabolism. 3. glyoxylate and dicarboxylate metabolism, 4. D-glutamine and D-glutamate metabolism, 5. nitrogen metabolism. 6. pyrimidine metabolism, 7. aminoacyl-tRNA biosynthesis, 8. pantothenate and CoA biosynthesis, 9. citrate cycle (TCA cycle), and 10. sphingolipid metabolism.

The pathway analysis carried out for 303 significant serum metabolites reported in five studies identified a total of 49 potentially involved metabolic pathways. As shown in Figure 1a, sphingolipid metabolism, as well as the citrate cycle (TCA cycle), were the most significantly affected metabolic pathways. In the case of AH samples, 29 metabolites reported in two studies corresponded to 18 potentially involved pathways. The most significant metabolic pathway identified in AH analysis (Figure 1b) was arginine biosynthesis, followed by alanine, aspartate and glutamate metabolism. A complete list of metabolic pathways involving metabolites identified in serum and AH samples is shown in Tables 3 and 4, respectively. The tables contain the number of metabolites involved in a given pathway and detected in serum or $\mathrm{AH}$, as well as the results of pathway analysis ( $p$-value and pathway impact value). 
Table 3. Metabolic pathways corresponding to metabolites identified in serum samples.

\begin{tabular}{|c|c|c|c|c|}
\hline Pathway & $\begin{array}{l}\text { No. of Metabolites in } \\
\text { the Pathway }\end{array}$ & $\begin{array}{l}\text { No. of Metabolites } \\
\text { Detected in Serum }\end{array}$ & $p$-Value & Pathway Impact \\
\hline Sphingolipid metabolism & 21 & 8 & 0.00013 & 0.57 \\
\hline Citrate cycle (TCA cycle) & 20 & 5 & 0.019 & 0.33 \\
\hline Linoleic acid metabolism & 5 & 2 & 0.056 & 1.0 \\
\hline Biosynthesis of unsaturated fatty acids & 36 & 6 & 0.068 & 0.0 \\
\hline Alanine, aspartate and glutamate metabolism & 28 & 5 & 0.072 & 0.094 \\
\hline Tryptophan metabolism & 41 & 6 & 0.11 & 0.17 \\
\hline Glyoxylate and dicarboxylate metabolism & 32 & 5 & 0.11 & 0.12 \\
\hline Tyrosine metabolism & 42 & 6 & 0.12 & 0.19 \\
\hline Glycerolipid metabolism & 16 & 3 & 0.14 & 0.29 \\
\hline Retinol metabolism & 17 & 3 & 0.16 & 0.46 \\
\hline Glycerophospholipid metabolism & 36 & 5 & 0.17 & 0.35 \\
\hline Pyruvate metabolism & 22 & 3 & 0.27 & 0.21 \\
\hline Glycine, serine and threonine metabolism & 33 & 4 & 0.28 & 0.26 \\
\hline Lysine degradation & 25 & 3 & 0.34 & 0.14 \\
\hline Thiamine metabolism & 7 & 1 & 0.45 & 0.0 \\
\hline Ascorbate and aldarate metabolism & 8 & 1 & 0.50 & 0.0 \\
\hline Taurine and hypotaurine metabolism & 8 & 1 & 0.50 & 0.43 \\
\hline Cysteine and methionine metabolism & 33 & 3 & 0.52 & 0.021 \\
\hline Beta-alanine metabolism & 21 & 2 & 0.52 & 0.45 \\
\hline One carbon pool by folate & 9 & 1 & 0.54 & 0.0 \\
\hline Steroid hormone biosynthesis & 85 & 7 & 0.56 & 0.023 \\
\hline Propanoate metabolism & 23 & 2 & 0.57 & 0.041 \\
\hline Phenylalanine metabolism & 10 & 1 & 0.57 & 0.0 \\
\hline Biotin metabolism & 10 & 1 & 0.57 & 0.15 \\
\hline Arginine and proline metabolism & 38 & 3 & 0.61 & 0.012 \\
\hline Glycolysis or Gluconeogenesis & 26 & 2 & 0.64 & 0.10 \\
\hline Galactose metabolism & 27 & 2 & 0.66 & 0.0 \\
\hline Alpha-linolenic acid metabolism & 13 & 1 & 0.67 & 0.0 \\
\hline Glutathione metabolism & 28 & 2 & 0.68 & 0.023 \\
\hline Arginine biosynthesis & 14 & 1 & 0.70 & 0.0 \\
\hline Glycosylphosphatidylinositol(GPI)-anchor biosynthesis & 14 & 1 & 0.70 & 0.0040 \\
\hline
\end{tabular}


Table 3. Cont

\begin{tabular}{|c|c|c|c|c|}
\hline Pathway & $\begin{array}{l}\text { No. of Metabolites in } \\
\text { the Pathway }\end{array}$ & $\begin{array}{l}\text { No. of Metabolites } \\
\text { Detected in Serum }\end{array}$ & $p$-Value & Pathway Impact \\
\hline Histidine metabolism & 16 & 1 & 0.75 & 0.0 \\
\hline Starch and sucrose metabolism & 18 & 1 & 0.79 & 0.073 \\
\hline Terpenoid backbone biosynthesis & 18 & 1 & 0.79 & 0.18 \\
\hline Pantothenate and CoA biosynthesis & 19 & 1 & 0.80 & 0.021 \\
\hline Arachidonic acid metabolism & 36 & 2 & 0.81 & 0.0 \\
\hline Fructose and mannose metabolism & 20 & 1 & 0.82 & 0.0 \\
\hline Selenocompound metabolism & 20 & 1 & 0.82 & 0.0 \\
\hline Ether lipid metabolism & 20 & 1 & 0.82 & 0.0 \\
\hline Amino sugar and nucleotide sugar metabolism & 37 & 2 & 0.82 & 0.0058 \\
\hline Pyrimidine metabolism & 39 & 2 & 0.84 & 0.057 \\
\hline Steroid biosynthesis & 42 & 2 & 0.87 & 0.0 \\
\hline Aminoacyl-tRNA biosynthesis & 48 & 2 & 0.92 & 0.17 \\
\hline Drug metabolism - cytochrome P450 & 55 & 2 & 0.95 & 0.0 \\
\hline Fatty acid elongation & 39 & 1 & 0.96 & 0.0 \\
\hline Fatty acid degradation & 39 & 1 & 0.96 & 0.0 \\
\hline Purine metabolism & 65 & 2 & 0.97 & 0.022 \\
\hline Primary bile acid biosynthesis & 46 & 1 & 0.98 & 0.0076 \\
\hline Fatty acid biosynthesis & 47 & 1 & 0.98 & 0.015 \\
\hline
\end{tabular}

Pathway impact values and $p$-values were obtained from metabolic pathway analysis performed with MetaboAnalyst 4.0 software. Pathways highlighted in bold were identified in the case of both serum and AH samples. 
Table 4. Metabolic pathways corresponding to metabolites identified in AH samples.

\begin{tabular}{|c|c|c|c|c|}
\hline Pathway & $\begin{array}{l}\text { No. of Metabolites in } \\
\text { the Pathway }\end{array}$ & $\begin{array}{l}\text { No. of Metabolites } \\
\text { Detected in AH }\end{array}$ & $p$-Value & Pathway Impact \\
\hline Arginine biosynthesis & 14 & 4 & 0.000028 & 0.30 \\
\hline Alanine, aspartate and glutamate metabolism & 28 & 2 & 0.058 & 0.21 \\
\hline Glyoxylate and dicarboxylate metabolism & 32 & 2 & 0.074 & 0.024 \\
\hline D-Glutamine and D-glutamate metabolism & 6 & 1 & 0.082 & 0.0 \\
\hline Nitrogen metabolism & 6 & 1 & 0.082 & 0.0 \\
\hline Pyrimidine metabolism & 39 & 2 & 0.10 & 0.06 \\
\hline Aminoacyl-tRNA biosynthesis & 48 & 2 & 0.15 & 0.0 \\
\hline Pantothenate and CoA biosynthesis & 19 & 1 & 0.24 & 0.0071 \\
\hline Citrate cycle (TCA cycle) & 20 & 1 & 0.25 & 0.12 \\
\hline Sphingolipid metabolism & 21 & 1 & 0.26 & 0.15 \\
\hline Pentose phosphate pathway & 22 & 1 & 0.27 & 0.0 \\
\hline Pyruvate metabolism & 22 & 1 & 0.27 & 0.0016 \\
\hline Lysine degradation & 25 & 1 & 0.30 & 0.14 \\
\hline Glycolysis or Gluconeogenesis & 26 & 1 & 0.31 & 0.0 \\
\hline Folate biosynthesis & 27 & 1 & 0.32 & 0.0 \\
\hline Arginine and proline metabolism & 38 & 1 & 0.42 & 0.056 \\
\hline Tryptophan metabolism & 41 & 1 & 0.45 & 0.0 \\
\hline Purine metabolism & 65 & 1 & 0.61 & 0.0 \\
\hline
\end{tabular}

Pathway impact values and $p$-values were obtained from metabolic pathway analysis performed with MetaboAnalyst 4.0 software. Pathways highlighted in bold were identified in the case of both serum and $\mathrm{AH}$ samples. 
Comparison of metabolic pathway analysis results for serum and AH samples identified 14 common pathways, mainly associated with decreased energy metabolism, increased oxidative stress, abnormal amino acid metabolism [37] or related to dopamine receptor D2 [35]. Metabolic pathways identified in the case of both serum and AH samples are highlighted in bold.

\section{Discussion}

\subsection{Experimental Models}

\subsubsection{Human Studies}

Blood serum is the most accessible material for omics studies in humans. However, due to the influence of various mechanisms, such as the blood-retinal barrier, only a certain proportion of physiological processes taking place in the eye will be reflected in the systemic circulation. On the other hand, the availability of ocular tissue specimens from human patients is limited, as they are usually obtained during highly invasive ophthalmological procedures, cataract surgeries in the case of the aqueous humor (AH) [41,42] and pars plana vitrectomies (PPV) for the vitreous humor (VH). $\mathrm{VH}$ is considered a particularly valuable research material given its anatomical and functional link to the retina and choroid. Unfortunately, the fact that VH can be obtained solely during PPV limits its availability to patients with the most serious complications, such as RRD or myopic retinoschisis (MRS). For the same reason, controls in the research on myopia are usually recruited among patients qualified for PPV because of different, theoretically unrelated conditions, such as macular hole (MH), epiretinal membrane (ERM) and RRD. Such an approach not only precludes an unbiased comparison between the results of myopia patients and truly healthy controls but also confines the insight into the pathogenesis of ocular disease to its final stages, rather than providing information about the initial, crucial steps in the transition from the norm to pathology. Furthermore, it is impossible to determine whether the changes observed in the biological material occurred secondarily to the chronic disease or were directly related to its pathogenesis.

\subsubsection{Animal Models}

A number of animal models have been developed to provide an insight into the pathogenesis of myopia, with the most widespread being form-deprived myopia (FDM) and lens-induced myopia (LIM). Both these models involve juvenile animals in which the processes of emmetropization are highly active and easy to disrupt. Emmetropization is a set of homeostatic control mechanisms that enable visual stimuli to be adequately focused on the retina. In brief, myopic defocus allows for hyperopic development, whereas hyperopic defocus is associated with myopic development [43]. Isolation of inputs from the higher brain by the blockage of ganglion cell signaling does not prevent the regulatory growth of the eye [44]. Optic nerve transection was shown to prevent myopia in LIM but not FDM, which implies that these two conditions may differ in terms of their underlying mechanisms [45]. On the other hand, parasympathectomy did not affect LIM development but prevented myopia in the FDM model [46]. While these findings might seem contradictory at first, they suggest that while some aspects of the eye growth regulation depend on the integration of visual stimuli within the central nervous system, at least some could occur independently at a local level.

In the FDM model, the treated eye is permanently covered with a translucent diffuser, while the other eye remains unobscured. Such treatment typically induces high myopia, with a decrease in spherical equivalent refraction (SER) down to $-5.0 \mathrm{D}$ or more depending on the species, albeit with substantial intersubject variability. However, the changes may also reflect the impact of light deprivation in the retina and do not necessarily correspond well with the mechanism involved in the development of myopia in humans. Nevertheless, the results of the FDM studies should not be neglected, as published evidence suggests that shorter time spent outdoors and disturbances in circadian rhythms may also contribute to myopia development $[47,48]$. 
In the LIM model, a negative power lens is placed before one eye of a juvenile animal, making it artificially hyperopic. This enforces emmetropization to refocus the light back on the retina, which is associated with rapid elongation of the affected eyeball. This condition simulates to a certain degree continuous near work of optic system in the human eye, perpetuated by growing educational pressure and popularization of smartphones and other hand-held devices even among the youngest children; this process is believed to contribute to an increase in myopia prevalence [49,50]. Differences and similarities between FDM and LIM, as well as inconsistent results obtained with the two models, are a matter of hot scientific debate, but this problem is beyond the scope of this review [46].

Various species have been used as the experimental models, among them guinea pig, chicks, tree shrew, mouse and tilapia. Among mammals, tree shrews are closely related to primates and have been considered as a surrogate for the latter in experimental studies.

Fox-Lrp2 deficient mice constitute an interesting model for processes being most likely responsible for the development of HM and PM. In one study involving this model, up to an eight-fold increase in the liquid vitreous fraction was observed in mutant mice when compared with the controls [15].

Chicks have been widely used as an animal model for myopia research; although the chick's eye differs substantially from the human eye, other than scleral structures, certain factors affecting normal refractive development appear to be similar.

The lack of an animal model that accurately simulates human pathological myopic retinopathy with late pathological changes significantly hinders the research on the underlying mechanisms of PM.

\subsection{Altered Pathways and Clinical Implications}

\subsubsection{Proteomics}

VH seems to be the best, relatively less invasively accessible surrogate material for research on human chorioretinal omics. In a study conducted by Wei et al. [10], patients subjected to PPV were classified based on the lack of PM signs (AL $<26.5 \mathrm{~mm}$ ), presence thereof $(26.5 \mathrm{~mm}<\mathrm{AL}<29.0 \mathrm{~mm}$ ) or occurrence of high PM ( $>29.0 \mathrm{~mm})$, and then subdivided according to a specific pathology: $\mathrm{MH}$, ERM, RRD or MRS. Expression of prostaglandin-H2 D-isomerase (PGDS) and glutathione peroxidase 3 (GPX3) in the PM groups was shown to be significantly lower than in the controls. The two enzymes are responsible for the scavenging of reactive oxygen species (ROS). The evidence from in vitro studies suggests that L-PGDS can potentially prevent oxidative stress and apoptosis-related neurodegenerative diseases. In turn, GPX3 is known to catalyze the reduction of organic hydroperoxides and hydrogen peroxide $\left(\mathrm{H}_{2} \mathrm{O}_{2}\right)$ to protect cells from oxidative damage [10].

Some similarities in the composition of proteins from crystallin, keratin and cytoskeletal families were found in the AH of cataract surgery patients with a history of glaucoma, diabetes mellitus or HM, but not in the controls [19]. In another study, the AH from patients with HM was shown to contain twice the amount of vitamin D-binding protein and transthyretin than in emmetropic controls [28].

Atropine has shown some potential to inhibit myopia progression in several animal models and two clinical trials in humans [51,52]. However, the clinical application of $1 \%$ atropine is limited by its serious adverse effects, and recently, the interest of researchers worldwide has been shifted from high-concentration ( $1 \%$ ) to low-concentration (0.01-0.05\%) atropine. Unfortunately, $0.01 \%$ atropine seems only to slow down the refractive changes associated with myopia, without an effect on the axial elongation of the eye. Given that myopia-related pathologies are mostly associated with eye length, we still do not know whether atropine could be an effective treatment for HM. Moreover, it is unclear how exactly this muscarinic antagonist exerts its effect on the eye. As muscarinic receptors are localized throughout the neural retina, and significant amounts of them are present in the RPE, this might be a target. According to Barathi et al. [53], another putative mechanism of atropine action might be its effect at the level of GABA transporter 1 (GAT-1), as elevated concentrations of the latter in the myopic retina were shown to undergo a significant reduction in response to atropine treatment [20]. GABA is the major inhibitory neurotransmitter in the retina and other parts of the central nervous system, and GABA 
signaling to dopaminergic amacrine neurons was shown to be associated with the reduction of their burst activity [54,55]. Furthermore, atropine was recently found to bind to $\alpha_{2 \mathrm{~A}}$-adrenergic receptors in amacrine cells as well. Meanwhile, $\alpha_{2 \mathrm{~A}}$-adrenergic receptors are expressed on dopaminergic neurons, and both atropine and $\alpha_{2 \mathrm{~A}}$-adrenoreceptor antagonists are known to stimulate dopamine (DA) release, whereas this process is strongly suppressed by $\alpha_{2 \mathrm{~A}}$-adrenoreceptor agonists [56]. The impact of DA and melatonin (Mel) on myopia is discussed in detail in Section 4.2.2 below.

The articles presenting only proteomic findings, without the interpretation thereof, are of lesser value from a clinical perspective. However, they may constitute a reference for future research, serving as a proteome database for various biological materials, such as tears from patients wearing orthokeratological lenses as a treatment for myopia and normal controls [9], chick cornea in FDM [12], chick $\mathrm{VH}$ [8] and guinea pig retina [24] during the emmetropization period.

\subsubsection{Metabolomics}

The authors of one study [40] stratified the results obtained with a guinea pig model for FDM according to a time point, as some of the animals were sacrificed on day 3 whereas others on day 14 since the FDM induction. In some guinea pigs, metabolite levels were significantly different from those found in the controls solely on day 3 (early responders), whereas in others, the significant differences were observed on both day 3 and 14 (continuous response) or solely on day 14 (late responders). In the early responders, mannose and glucose levels in FDM eyes were significantly higher than in control retinas, whereas concentrations of arabinose, urea, tyrosine and glutamic acid remained significantly lower. In the continuous response group, significantly lower levels of threonine, valine, isoleucine, alanine and malic acid were observed, and late responders presented with significantly lower concentrations of some fatty acids, namely arachidic, octadecenoic, octadecanoic, arachidonic (ARA), hexadecanoic, tetradecanoic and octadecadienoic acid. The observation that concentrations of some metabolites were significantly altered at some, albeit not all, points of the study constitutes another argument to support the hypothesis that research on subjects with already developed, "mature" myopia might not necessarily identify critical factors responsible for the development of this condition at its earlier stages.

Human AH has been a subject of metabolomics studies, both with GC-MS [34] and combined LC-MS, CE-MS [33] separation. In these studies, hundreds of significant associations were found on metabolite-metabolite correlation analysis; while the paucity of the data might hinder any definitive conclusions, it also adds considerably to our knowledge of human eye metabolome and its complexity.

The effects of two neurotransmitters, dopamine (DA) and melatonin (Mel), acting as mutual inhibitors in the regulation of circadian rhythms, on ocular diseases, especially myopia, have been studied in various animal models. To this date, the presence of specific DA and Mel receptors has been confirmed in frog [57,58], chick [59], guinea pig [60], mammalian [54,61] and human [62] retinal cells. Dopaminergic agents, administered either topically or systemically, were shown to inhibit or at least delay the development of form-deprivation myopia. Kearney et al. [39] were the first who demonstrated that similar relationships probably exist in humans, based on the observation that higher serum concentrations of Mel in the morning were associated with the occurrence of myopia in young adults.

Analyzing differences in the serum metabolic profiles of Chinese myopes and high myopes, Ke et al. [37] identified the citrate cycle as the most impacted pathway and postulated that this pathway might be involved in the axial length increase in humans. Citric acid intermediates in energy metabolism and corresponding elevated extracellular adenosine levels translate to greater adenosine receptor activation. This observation is supported by the results of animal experiments and findings from a few clinical trials; specifically, adenosine antagonist, 7-methylxanthine, was shown to reduce the eye elongation rate in form-deprivation myopia in macaque [63] and pigmented rabbit models [64], as well as in myopic children [65]. As circadian rhythms, or, more specifically, daylight exposure, are one of the most important modulators of adenosine levels in the mammalian retina, further research is needed to validate the importance of the findings mentioned above. 
Liu et al. [38] reported on differences in the serum metabolomes of patients with choroidal neovascularization in the course of age-related macular degeneration, polypoidal choroidal vasculopathy and pathological myopia (PM). Thiamine metabolism, arginine and proline metabolism, as well as purine metabolism, were identified as the main contributors to CNV in PM development.

Most of the altered pathways identified in the study conducted by Du et al. [36] were related to oxidative stress (five pathways) and dopamine receptor D2 (five pathways), which provides a novel insight into the metabolic mechanisms involved in the occurrence, development and treatment of myopia.

Dai et al. [35] identified two metabolites, $\gamma$-glutamyltyrosine and 12-oxo-20-trihydroxy-leukotriene B4, as potential biomarkers of myopia. In turn, the metabolic alterations associated with high myopia included phospholipid, diacylglycerol, amino acid and vitamin metabolism.

\subsection{Analytical Aspects}

\subsubsection{Proteomics}

The majority of proteomics studies are based on mass spectrometry combined with liquid chromatography (LC-MS). Most of these studies centered around the analysis of protein expression and interactions, protein post-translation modifications (PTMs) or enzymatic functions. Mass spectrometry enables us to track changes occurring throughout the proteome in various disease entities, including myopia. From a clinical trial perspective, a crucial aspect of proteomics analyses is quantitative information about the levels of proteins that differ significantly between the studied groups. Proteomic analyses based on mass spectrometry used in clinical trials can be divided into two categories. One of them is non-targeted analysis (data-dependent acquisition) (DDA) focusing on the use of metabolic labeling, chemical labeling or label-free protocols for the quantification of proteins or peptides. Another category is targeted analysis (data-independent acquisition) (DIA) based on the quantitative measurement of retention time and mass-to-charge with the MS equipment [66]. In the clinical aspect, most DDA strategies are based primarily on chemical labeling using isobaric tags-for example, tandem mass tags (TMT), isobaric tags for relative and absolute quantitation (iTRAQ) and others. Another method to quantify proteins and peptides in DDA analyses is label-free (LF) quantification. In this method, no chemicals are used for labeling, but quantitative information is obtained based on the measurement of the chromatographic peak's area and integration with MS analysis [67]. Sequential window acquisition of all the theoretical ionic spectra (SWATH) is a method similar to LF. SWATH-MS is based on the cyclic acquisition of precursor ions with solid isolation windows that cover the entire $\mathrm{m} / \mathrm{z}$ range and comparison of the spectra with the spectral library [68]. On the other hand, targeted proteomics uses two approaches: selected reaction monitoring (SRM) and parallel reaction monitoring (PRM). While in the PRM, the instrument records all peptide fragments from the analytical sample with a high mass resolution, only a single fragment ion is considered in the SRM [69].

Unlike in metabolomics studies, most proteomic studies included in this review were carried out on animal material. Animal specimens are easier to obtain than clinical samples, and the amount of analyte is larger. While proteomic analyses of human specimens were limited to vitreous $[10,32]$ and aqueous humor $[19,26,28]$, other materials, such as sclera [22,23], retina [17] and cornea [12], were also included in animal studies. Both studies in humans and those involving animal models can be divided into non-targeted and targeted analyses. As mentioned above, the non-targeted approach is characterized by different methods of protein and peptide quantification. Most of the studies included in this review used protein separation on polyacrylamide gel with electrophoresis, followed by protein digestion and mass spectrometry analysis. These methods are commonly used for proteomic analysis and protein separation. One of the two most widespread methods from this group is sodium dodecyl sulfate-polyacrylamide gel electrophoresis (SDS-PAGE). In SDS-PAGE, proteins are separated in a polyacrylamide gel based on their molecular weight [70]. The second method is the two-dimensional 
gel electrophoresis (2D-PAGE). In this method, proteins are separated based on their isoelectric point (pI) value in the first dimension, followed by the relative molecular weight-based separation in the second dimension [70]. The 2D-PAGE is quite often used in the preparation of tissue samples. Both SDS-PAGE and 2D-PAGE are commonly used in the examination of ocular tissues, with the latter employed somehow more often than the former $[13,16,31]$. However, both these methods represent quite an old approach to proteome analysis with relatively low throughput. With the progress in mass spectrometry, especially with the development of high-resolution mass spectrometers, this type of analysis is being abandoned, particularly in clinical trials. As mentioned above, an important aspect of clinical trials is a between-group comparison of protein levels. Thus, the methods for protein quantification have been used increasingly nowadays, with the most popular being the label-free technique and chemical labeling. The LF method was used, among others, to analyze the vitreous and retina from both humans $[10,32]$ and animals $[15,21,27]$. In turn, chemical tags found application in the analysis of the proteomic profiles of the retina, vitreous and aqueous humor. Isotope-coded protein label (ICPL) was used in the studies of chick retina and vitreous humor $[17,18]$, whereas iTRAQ was applied to analyze aqueous humor from patients with cataract $[19,26]$ and atropine-treated mice with myopia [20]. While the latter analysis used the DDA approach, the SWATH analyses, especially those aimed at the creation of spectral libraries, involved the DIA approach. In most cases, the libraries were created based on vitreous and corneal samples from chicks $[8,12]$ and retina from pigs $[24,30]$. Furthermore, this method was also used to analyze human tears in patients wearing orthokeratology lenses as myopia treatment [9]. The targeted approach, especially multiple reaction monitoring (MRM), was also used in the analysis of the retina from chicks with one myopic and one hyperopic eye [17]. Similar analyses were also performed on pig retina [24,30].

\subsubsection{Metabolomics}

Metabolomics studies usually involve nuclear magnetic resonance (NMR) or mass spectrometry. NMR is suitable for the simultaneous identification and quantification of metabolites from different classes (e.g., amino acids, vitamins, thiols, carbohydrates), albeit in micromolar or higher concentrations [71]. MS has better sensitivity and dynamic range than NMR, but prior to the detection, metabolites usually need to be separated with liquid chromatography (LC-MS), gas chromatography (GC-MS) or capillary electrophoresis (CE-MS). Depending on the separation method, different classes of metabolites can be quantified. CE-MS is more suitable for polar and ionic, GC-MS for volatile and LC-MS for labile and non-volatile compounds. Consequently, to measure metabolites belonging to different classes and to increase the metabolome coverage, different separation methods need to be applied simultaneously [72]. Furthermore, it is noteworthy that the number of metabolites found in AH separation may differ depending on whether LC-MS, CE-MS or GC-MS was used as a separation method. For example, in one study [34], a total of 242 metabolites were initially identified in AH by means of GC-MS, with only 29 eventually found to be statistically significant. Meanwhile, in another study using CE-MS and LC-MS [33], the numbers of statistically significant AH metabolites exceeded 40 and 20, respectively. These discrepancies in the overall number of metabolites and the number of statistically significant metabolites are in part a consequence of the different statistical approaches used in various separation methods. In LC-MS and CE-MS, statistics are performed first, followed by the identification of distinctive metabolites. Meanwhile, the total number of distinctive metabolites is determined first in GC-MS, and then, those which are statistically significant are selected.

Regardless of the used method, different approaches to metabolome analysis exist. The most comprehensive approach is metabolic fingerprinting, the aim of which is to measure as many metabolites in the sample as possible. In this approach, all steps of the analytical protocol are optimized to facilitate the measurement of a large number of metabolites with appropriate quality [73]. Metabolic profiling methods focus on the measurement of metabolites from a particular class (e.g., fatty acids) [74] or metabolic pathway (e.g., arachidonic acid pathway) [75]. In MS-based fingerprinting studies, the presence of a reference group is necessary. The result is semi-quantitative, 
i.e., metabolites' abundances between the controls and the case group are compared [73]. In contrast, metabolites determined by means of profiling or target analysis can be quantified, but respective analytical standards need to be used. The use of the standards is also indispensable to fully confirm the metabolite identification [76].

Only a few published studies have used metabolomic techniques to study myopia. To the best of our knowledge, none of the previous studies used NMR to study this condition. The vast majority of researchers applied untargeted methods, such as CE-MS [33], LC-MS [33,35,36] or GC-MS [34,37,38], to analyze human serum [35-38] or AH $[33,34]$. We found only one published study using a targeted method to analyze human serum [39] and only one untargeted study in an animal model [40].

The protocol of sample preparation for untargeted analysis depends on the type of examined material and chromatographic method applied. GC-MS differs considerably from the other two separation techniques in terms of sample preparation. A major limitation of GC-MS stems from the fact that this method is only capable of analyzing volatile compounds or those that can be made volatile by derivatization; this significantly extends and hinders the preparation procedure. Frequently, the samples are mixed with methanol [34,37] or methanol/chloroform mixture [38] and internal standard and then completely dried in a vacuum concentrator. Subsequently, the material is derivatized using a two-step procedure, methoxication and silylation. First, the samples are incubated with methoxyamine in pyridine, and then, BSTFA [34] or MSTFA [37,38] reagent containing $1 \%$ TMCS is added, and samples are again incubated. Finally, the samples are centrifuged, and the supernatants are transferred to vials and analyzed.

On the other hand, sample preparation for LC-MS involves mostly the addition of an organic solvent/solvent mixture to precipitate proteins and to extract metabolites. Barbas-Bernardos et al. used a minimal sample preparation protocol. For CE-MS analysis, the samples were mixed with the internal standard solution, and the material for LC-MS was only centrifuged, and then, the supernatant was analyzed directly [33]. The more complex preparation procedures described in the literature include deproteinization with methanol [35], methanol/chloroform or methanol/acetonitrile/water extraction buffer [36], followed by drying under nitrogen in most cases [35,36]. Then, the residues are dissolved and centrifuged, and the supernatants are used for further analyses [35].

In the only reported untargeted analysis based on an animal model, Yang et al. used GC-TOF-MS for retinal profiling in guinea pigs. The study required an extra step at the sample preparation stage; specifically, the samples of the retina were homogenized in a solvent mixture (chloroform/methanol/water) and centrifuged. Then, the supernatants were mixed with two internal standards and vacuum dried. The residues were derivatized as well [40].

In targeted research, the sample preparation procedure depends on the analyzed metabolite. Kearney et al. analyzed serum concentrations of dopamine and melatonin using liquid chromatography followed by on-line solid-phase extraction and tandem mass spectrometry analysis. In their study, the serum was only preserved at a final concentration of $0.1 \%$ ascorbic acid solution $0.1 \mathrm{M}$ hydrochloric acid to prevent degradation of dopamine [39].

\section{Conclusions}

We propose to compare the $\mathrm{AH}, \mathrm{VH}$ and serum metabolomic/proteomic profiles, especially from patients, where possible. Simultaneous metabolomics and proteomics analysis of these biological materials from the same patient might be of additional value, as it will enable a more holistic understanding of the disease. From the clinical perspective, the focus should be on the acquisition of biological material including serum, $\mathrm{AH}$ and $\mathrm{VH}$ from patients undergoing surgery. This might facilitate the discovery of new paths of myopia development as well as indicate new therapeutic targets. A combined approach using complementary separation techniques should also be considered. Especially in humans, studies on proteomics of serum and metabolomics of vitreous humor in myopia are lacking. Moreover, reports on metabolomics in animal models are scarce. Further studies on DA and mel-atropine interactions seem to be of particular importance from the clinical practitioner's perspective. 
Funding: This research received no external funding

Conflicts of Interest: The authors declare no conflict of interest.

\section{Abbreviations}

\begin{tabular}{ll} 
2D-PAGE & two-dimensional gel electrophoresis \\
AH & aqueous humor \\
CE & capillary electrophoresis \\
DDA & data-dependent acquisition \\
DIA & data-independent acquisition \\
ERM & epiretinal membrane \\
FDM & form-deprived myopia \\
VH & vitreous humor \\
GC & gas chromatography \\
ICPL & isotope-coded protein label \\
iTRAQ & isobaric tags for relative and absolute quantitation \\
HM & high myopia \\
MH & macular hole \\
LC & liquid chromatography \\
LIM & lens-induced myopia \\
LF & label-free \\
MS & mass spectrometry \\
MALDI-TOF & matrix-assisted laser desorption/ionization \\
MRS & myopic retinoschisis \\
MRM & multiple reaction monitoring \\
NMR & nuclear magnetic resonance \\
PCV & polypoidal choroidal vasculopathy \\
PRM & parallel reaction monitoring \\
PM & pathological myopia \\
PPV & pars plana vitrectomy \\
PTM & post-translation modifications \\
RPE & retinal pigment epithelium \\
RRD & rhegmatogenous retinal detachment \\
SRM & selected reaction monitoring \\
SER & spherical equivalent refraction \\
SDS-PAGE & sodium dodecyl sulfate-polyacrylamide gel electrophoresis \\
SWATH & sequential window acquisition of all theoretical fragment ion spectra \\
TMT & tandem mass tags \\
\hline
\end{tabular}

\section{References}

1. Ohno-Matsui, K.R.; Kawasaki, J.B.; Jonas, C.M.; Cheung, S.M.; Saw, V.J.; Verhoeven, C.C.; Klaver, M.; Moriyama, K.; Shinohara, Y.; Kawasaki, M.; et al. International photographic classification and grading system for myopic maculopathy. Am. J. Ophthalmol. 2015, 159, 877-883. [CrossRef] [PubMed]

2. Ohno-Matsui, K. Pathologic Myopia. Asia Pac. J. Ophthalmol. 2016, 5, 415-423. [CrossRef] [PubMed]

3. Chen, M.; Wu, A.; Zhang, L.; Wang, W.; Chen, X.; Yu, X.; Wang, K. The increasing prevalence of myopia and high myopia among high school students in Fenghua city, eastern China: A 15-year population-based survey. BMC Ophthalmol. 2018, 18, 159. [CrossRef]

4. Rudnicka, A.R.; Kapetanakis, V.V.; Wathern, A.K.; Logan, N.S.; Gilmartin, B.; Whincup, P.H.; Cook, D.G.; Owen, C.G. Global variations and time trends in the prevalence of childhood myopia, a systematic review and quantitative meta-analysis: Implications for aetiology and early prevention. Br. J. Ophthalmol. 2016, 100, 882-890. [CrossRef]

5. Holden, B.A.; Fricke, T.R.; Wilson, D.A.; Jong, M.; Naidoo, K.S.; Sankaridurg, P.; Wong, T.Y.; Naduvilath, T.J.; Resnikoff, S.G. Prevalence of Myopia and High Myopia and Temporal Trends from 2000 through 2050. Ophthalmology 2016, 123, 1036-1042. [CrossRef] [PubMed] 
6. Kowalczyk, T.; Ciborowski, M.; Kisluk, J.; Kretowski, A.; Barbas, C. Mass spectrometry based proteomics and metabolomics in personalized oncology. Biochim. Biophys. Acta Mol. Basis Dis. 2020, 1866, 165690. [CrossRef] [PubMed]

7. Nielsen, K.; Vorum, H.; Fagerholm, P.; Birkenkamp-Demtröder, K.; Honoré, B.; Ehlers, N.; Orntoft, T.F. Proteome profiling of corneal epithelium and identification of marker proteins for keratoconus, a pilot study. Exp. Eye Res. 2006, 82, 201-219. [CrossRef]

8. Cheung, J.K.; Li, K.K.; Zhou, L.; To, C.H.; Lam, T.C. Data on protein changes of chick vitreous during normal eye growth using data-independent acquisition (SWATH-MS). Data Brief 2020, 30, 105576. [CrossRef]

9. Tse, J.S.; Lam, T.C.; Cheung, J.K.; Sze, Y.H.; Wong, T.K.; Chan, H.H. Data on assessment of safety and tear proteome change in response to orthokeratology lens-Insight from integrating clinical data and next generation proteomics. Data Brief 2020, 29, 105186. [CrossRef]

10. Wei, Q.; Zhang, T.; Fan, J.; Jiang, R.; Chang, Q.; Hong, J.; Xu, G. Pathological myopia-induced antioxidative proteins in the vitreous humor. Ann. Transl. Med. 2020, 8, 193. [CrossRef]

11. Frost, R.M.; Norton, T.T. Differential protein expression in tree shrew sclera during development of lens-induced myopia and recovery. Mol. Vis. 2007, 13, 1580-1588. [PubMed]

12. Kang, B.S.; Lam, T.C.; Cheung, J.K.; Li, K.K.; Kee, C.S. Data on corneal proteome and differentially expressed corneal proteins in highly myopic chicks using a data independent quantification approach. Data Brief 2019, 26, 104478. [CrossRef] [PubMed]

13. Li, S.; Wu, J.; Ding, H.; Liao, A.; He, H.; Stell, W.K.; Zhong, X. Flicker downregulates the content of crystallin proteins in form-deprived C57BL/6 mouse retina. Exp. Eye Res. 2012, 101, 1-8. [CrossRef] [PubMed]

14. Jostrup, R.; Shen, W.; Burrows, J.T.; Sivak, J.G.; McConkey, B.J.; Singer, T.D. Identification of myopia-related marker proteins in tilapia retinal, RPE, and choroidal tissue following induced form deprivation. Curr. Eye Res. 2009, 34, 966-975. [CrossRef] [PubMed]

15. Cases, O.; Obry, A.; Ben-Yacoub, S.; Augustin, S.; Joseph, A.; Toutirais, G.; Simonutti, M.; Christ, A.; Cosette, P.; Kozyraki, R. Impaired vitreous composition and retinal pigment epithelium function in the FoxG1::LRP2 myopic mice. Biochim. Biophys. Acta Mol. Basis Dis. 2017, 1863, 1242-1254. [CrossRef]

16. Lam, T.C.; Li, K.K.; Lo, S.C.; Guggenheim, J.A.; To, C.H. Application of fluorescence difference gel electrophoresis technology in searching for protein biomarkers in chick myopia. J. Proteome Res. 2007, 6, 4135-4149. [CrossRef]

17. Yu, F.J.; Lam, T.C.; Sze, A.Y.; Li, K.K.; Chun, R.K.; Shan, S.W.; To, C.H. Alteration of retinal metabolism and oxidative stress may implicate myopic eye growth: Evidence from discovery and targeted proteomics in an animal model. J. Proteom. 2020, 221, 103684. [CrossRef]

18. Yu, F.J.; Lam, T.C.; Liu, L.Q.; Chun, R.K.; Cheung, J.K.; Li, K.K.; To, C.H. Isotope-coded protein label based quantitative proteomic analysis reveals significant up-regulation of apolipoprotein A1 and ovotransferrin in the myopic chick vitreous. Sci. Rep. 2017, 7, 12649. [CrossRef]

19. Xiang, M.; Zhang, X.; Li, Q.; Wang, H.; Zhang, Z.; Han, Z.; Ke, M.; Chen, X. Identification of proteins in the aqueous humor associated with cataract development using iTRAQ methodology. Mol. Med. Rep. 2017, 15, 3111-3120. [CrossRef]

20. Barathi, V.A.; Chaurasia, S.S.; Poidinger, M.; Koh, S.K.; Tian, D.; Ho, C.; Iuvone, P.M.; Beuerman, R.W.; Zhou, L. Involvement of GABA transporters in atropine-treated myopic retina as revealed by iTRAQ quantitative proteomics. J. Proteome Res. 2014, 13, 4647-4658. [CrossRef]

21. Riddell, N.; Faou, P.; Crewther, S.G. Short term optical defocus perturbs normal developmental shifts in retina/RPE protein abundance. BMC Dev. Biol. 2018, 18, 18. [CrossRef] [PubMed]

22. Zhou, X.; Ye, J.; Willcox, M.D.; Xie, R.; Jiang, L.; Lu, R.; Shi, J.; Bai, Y.; Qu, J. Changes in protein profiles of guinea pig sclera during development of form deprivation myopia and recovery. Mol. Vis. 2010, 16, 2163-2174. [PubMed]

23. Frost, R.M.; Norton, T.T. Alterations in protein expression in tree shrew sclera during development of lens-induced myopia and recovery. Investig. Ophthalmol. Vis. Sci. 2012, 53, 322-336. [CrossRef] [PubMed]

24. Shan, S.W.; Tse, D.Y.; Zuo, B.; To, C.H.; Liu, Q.; McFadden, S.A.; Chun, R.K.; Bian, J.; Li, K.K.; Lam, T.C. Data on differentially expressed proteins in retinal emmetropization process in guinea pig using integrated SWATH-based and targeted-based proteomics. Data Brief 2018, 21, 1750-1755. [CrossRef] 
25. Bertrand, E.; Fritsch, C.; Diether, S.; Lambrou, G.; Müller, D.; Schaeffel, F.; Schindler, P.; Schmid, K.L.; van Oostrum, J.; Voshol, H. Identification of apolipoprotein A-I as a "STOP" signal for myopia. Mol. Cell. Proteom. 2006, 5, 2158-2166. [CrossRef]

26. Ji, Y.; Rong, X.; Ye, H.; Zhang, K.; Lu, Y. Proteomic analysis of aqueous humor proteins associated with cataract development. Clin. Biochem. 2015, 48, 1304-1309. [CrossRef]

27. Riddell, N.; Faou, P.; Murphy, M.; Giummarra, L.; Downs, R.A.; Rajapaksha, H.; Crewther, S.G. The retina/RPE proteome in chick myopia and hyperopia models: Commonalities with inherited and age-related ocular pathologies. Mol. Vis. 2017, 23, 872-888.

28. Duan, X.; Lu, Q.; Xue, P.; Zhang, H.; Dong, Z.; Yang, F.; Wang, N. Proteomic analysis of aqueous humor from patients with myopia. Mol. Vis. 2008, 14, 370-377.

29. Wu, Y.; Lam, C.S.; Tse, D.Y.; Tom, C.H.; Liu, Q.; McFadden, S.A.; Chun, R.K.; Li, K.K.; Bian, J.; Lam, C. Early quantitative profiling of differential retinal protein expression in lens-induced myopia in guinea pig using fluorescence difference two-dimensional gel electrophoresis. Mol. Med. Rep. 2018, 17, 5571-5580. [CrossRef]

30. Shan, S.W.; Tse, D.Y.; Zuo, B.; To, C.H.; Liu, Q.; McFadden, S.A.; Chun, R.K.; Bian, J.; Li, K.K.; Lam, T.C. Integrated SWATH-based and targeted-based proteomics provide insights into the retinal emmetropization process in guinea pig. J. Proteom. 2018, 181, 1-15. [CrossRef]

31. Zhou, Y.Y.; Chun, R.K.M.; Wang, J.C.; Zuo, B.; Li, K.K.; Lam, T.C.; Liu, Q.; To, C.H. Proteomic analysis of chick retina during early recovery from lens-induced myopia. Mol. Med. Rep. 2018, 18, 59-66. [CrossRef] [PubMed]

32. Wei, Q.; Jiang, C.; Ye, X.; Huang, X.; Jin, H.; Xu, G. Vitreous Proteomics Provides New Insights into Antivascular Endothelial Growth Factor Therapy for Pathologic Myopia Choroid Neovascularization. J. Interferon Cytokine Res. 2019, 39, 786-796. [CrossRef]

33. Barbas-Bernardos, C.; Armitage, E.G.; García, A.; Mérida, S.; Navea, A.; Bosch-Morell, F.; Barbas, C. Looking into aqueous humor through metabolomics spectacles-exploring its metabolic characteristics in relation to myopia. J. Pharm. Biomed. Anal 2016, 127, 18-25. [CrossRef] [PubMed]

34. Ji, Y.; Rao, J.; Rong, X.; Lou, S.; Zheng, Z.; Lu, Y. Metabolic characterization of human aqueous humor in relation to high myopia. Exp. Eye Res. 2017, 159, 147-155. [CrossRef] [PubMed]

35. Dai, L.; Yang, W.; Qin, X.; Li, Y.; Cao, H.; Zhou, C.; Wang, Y. Serum metabolomics profiling and potential biomarkers of myopia using LC-QTOF/MS. Exp. Eye Res. 2019, 186, 107737. [CrossRef]

36. Du, B.; Jin, N.; Zhu, X.; Lu, D.; Jin, C.; Li, Z.; Han, C.; Zhang, Y.; Lai, D.; Liu, K.; et al. A prospective study of serum metabolomic and lipidomic changes in myopic children and adolescents. Exp. Eye Res. 2020, 199, 108182. [CrossRef]

37. Ke, C.; Xu, H.; Chen, Q.; Zhong, H.; Pan, C.W. Serum metabolic signatures of high myopia among older Chinese adults. Eye 2020, 2020,1-8. [CrossRef]

38. Liu, K.; Fang, J.; Jin, J.; Zhu, S.; Xu, X.; Xu, Y.; Ye, B.; Lin, S.H.; Xu, X. Serum Metabolomics Reveals Personalized Metabolic Patterns for Macular Neovascular Disease Patient Stratification. J. Proteome Res. 2020, 19, 699-707. [CrossRef]

39. Kearney, S.; O’Donoghue, L.; Pourshahidi, L.K.; Cobice, D.; Saunders, K.J. Myopes have significantly higher serum melatonin concentrations than non-myopes. Ophthalmic. Physiol. Opt. 2017, 37, 557-567. [CrossRef]

40. Yang, J.; Reinach, P.S.; Zhang, S.; Pan, M.; Sun, W.; Liu, B.; Li, F.; Li, X.; Zhao, A.; Chen, T.; et al. Changes in retinal metabolic profiles associated with form deprivation myopia development in guinea pigs. Sci. Rep. 2017, 7, 2777. [CrossRef]

41. Pietrowska, K.; Dmuchowska, D.A.; Krasnicki, P.; Mariak, Z.; Kretowski, A.; Ciborowski, M. Analysis of pharmaceuticals and small molecules in aqueous humor. J. Pharm. Biomed. Anal. 2018, 159, 23-36. [CrossRef]

42. Pietrowska, K.; Dmuchowska, D.A.; Samczuk, P.; Kowalczyk, T.; Krasnicki, P.; Wojnar, M.; Skowronska, A.; Mariak, Z.; Kretowski, A.; Ciborowski, M. LC-MS-Based Metabolic Fingerprinting of Aqueous Humor. J. Anal. Methods Chem. 2017, 2017, 6745932. [CrossRef] [PubMed]

43. Wallman, J.; Winawer, J. Homeostasis of eye growth and the question of myopia. Neuron 2004, 43, 447-468. [CrossRef] [PubMed]

44. Schmid, L.K.; Wildsoet, C.F. Effects on the compensatory responses to positive and negative lenses of intermittent lens wear and ciliary nerve section in chicks. Vis. Res. 1996, 36, 1023-1036. [CrossRef]

45. Wildsoet, C.; Wallman, J. Choroidal and scleral mechanisms of compensation for spectacle lenses in chicks. Vis. Res. 1995, 35, 1175-1194. [CrossRef] 
46. Morgan, G.I.; Ashby, R.S.; Nickla, D.L. Form deprivation and lens-induced myopia: Are they different? Ophthalmic. Physiol. Opt. 2013, 33, 355-361. [CrossRef]

47. Rose, K.A.; Morgan, I.G.; Ip, J.; Kifley, A.; Huynh, S.; Smith, W.; Mitchell, P. Outdoor activity reduces the prevalence of myopia in children. Ophthalmology 2008, 115, 1279-1285. [CrossRef]

48. Li, S.M.; Li, H.; Li, S.Y.; Liu, L.R.; Kang, M.T.; Wang, Y.P.; Zhang, F.; Zhan, S.Y.; Gopinath, B.; Mitchell, P.; et al. Time Outdoors and Myopia Progression Over 2 Years in Chinese Children: The Anyang Childhood Eye Study. Investig. Ophthalmol. Vis. Sci. 2015, 56, 4734-4740. [CrossRef]

49. Saw, S.M.; Hong, R.Z.; Zhang, M.Z.; Fu, Z.F.; Ye, M.; Tan, D.; Chew, S.J. Near-work activity and myopia in rural and urban schoolchildren in China. J. Pediatr. Ophthalmol. Strabismus 2001, 38, 149-155.

50. Saw, S.M.; Chua, W.H.; Hong, C.Y.; Wu, H.M.; Chan, W.Y.; Chia, K.S.; Stone, R.A.; Tan, D. Nearwork in early-onset myopia. Investig. Ophthalmol. Vis. Sci. 2002, 43, 332-339.

51. Chia, A.; Lu, Q.S.; Tan, D. Five-Year Clinical Trial on Atropine for the Treatment of Myopia 2: Myopia Control with Atropine 0.01\% Eyedrops. Ophthalmology 2016, 123, 391-399. [CrossRef] [PubMed]

52. Yam, J.C.; Jiang, Y.; Tang, S.M.; Law, A.K.P.; Chan, J.J.; Wong, E.; Ko, S.T.; Young, A.L.; Tham, C.C.; Chen, L.J.; et al. Low-Concentration Atropine for Myopia Progression (LAMP) Study: A Randomized, Double-Blinded, Placebo-Controlled Trial of 0.05\%, 0.025\%, and 0.01\% Atropine Eye Drops in Myopia Control. Ophthalmology 2019, 126, 113-124. [CrossRef]

53. Barathi, S.R.; Weon, P.W.Y.; Rebekah, R.W. Beuerman Muscarinic Regulation of Epidermal Growth Factor Receptor in Mammalian Retinal Pigment Epithelial (RPE) Cells. Investig. Ophthalmol. Vis. Sci. 2008, 49, 3535.

54. Atkinson, L.C.; Feng, J.; Zhang, D.Q. Functional integrity and modification of retinal dopaminergic neurons in the rd1 mutant mouse: Roles of melanopsin and GABA. J. Neurophysiol. 2013, 109, 1589-1599. [CrossRef] [PubMed]

55. Zhang, Q.D.; Zhou, T.R.; McMahon, D.G. Functional heterogeneity of retinal dopaminergic neurons underlying their multiple roles in vision. J. Neurosci. 2007, 27, 692-699. [CrossRef]

56. Mathis, U.; Feldkaemper, M.; Wang, M.; Schaeffel, F. Studies on retinal mechanisms possibly related to myopia inhibition by atropine in the chicken. Graefe's Arch. Clin. Exp. Ophthalmol. 2020, 258, 319-333. [CrossRef] [PubMed]

57. Wiechmann, F.A.; Wirsig-Wiechmann, C.R. Multiple cell targets for melatonin action in Xenopus laevis retina: Distribution of melatonin receptor immunoreactivity. Vis. Neurosci. 2001, 18, 695-702. [CrossRef] [PubMed]

58. Wiechmann, F.A.; Rada, J.A. Melatonin receptor expression in the cornea and sclera. Exp. Eye Res. 2003, 77, 219-225. [CrossRef]

59. Rada, J.A.; Wiechmann, A.F. Melatonin receptors in chick ocular tissues: Implications for a role of melatonin in ocular growth regulation. Investig. Ophthalmol. Vis. Sci. 2006, 47, 25-33. [CrossRef]

60. Wang, F.; Zhou, J.; Lu, Y.; Chu, R. Effects of $530 \mathrm{~nm}$ green light on refractive status, melatonin, MT1 receptor, and melanopsin in the guinea pig. Curr. Eye Res. 2011, 36, 103-111. [CrossRef]

61. Freedman, M.S.; Lucas, R.J.; Soni, B.; von Schantz, M.; Muñoz, M.; David-Gray, Z.; Foster, R. Regulation of mammalian circadian behavior by non-rod, non-cone, ocular photoreceptors. Science 1999, 284, 502-504. [CrossRef] [PubMed]

62. Stormann, T.M.; Gdula, D.C.; Weiner, D.M.; Brann, M.R. Molecular cloning and expression of a dopamine D2 receptor from human retina. Mol. Pharmacol. 1990, 37, 1-6.

63. Hung, L.F.; Arumugam, B.; Ostrin, L.; Patel, N.; Trier, K.; Jong, M.; Smith, E.L., III. The Adenosine Receptor Antagonist, 7-Methylxanthine, Alters Emmetropizing Responses in Infant Macaques. Investig. Ophthalmol. Vis. Sci. 2018, 59, 472-486. [CrossRef] [PubMed]

64. Nie, H.H.; Huo, L.J.; Yang, X.; Gao, Z.Y.; Zeng, J.W.; Trier, K.; Cui, D.M. Effects of 7-methylxanthine on form-deprivation myopia in pigmented rabbits. Int. J. Ophthalmol. 2012, 5, 133-137. [PubMed]

65. Trier, K.; Munk Ribel-Madsen, S.; Cui, D.; Brøgger Christensen, S. Systemic 7-methylxanthine in retarding axial eye growth and myopia progression: A 36-month pilot study. J. Ocul. Biol. Dis. Inform. 2008, 1, 85-93. [CrossRef]

66. Erickson, B.K.; Rose, C.M.; Braun, C.R.; Erickson, A.R.; Knott, J.; McAlister, G.C.; Wühr, M.; Paulo, J.A.; Everley, R.A.; Gygi, S.P. A Strategy to Combine Sample Multiplexing with Targeted Proteomics Assays for High-Throughput Protein Signature Characterization. Mol. Cell 2017, 65, 361-370. [CrossRef] 
67. Neilson, K.A.; Ali, N.A.; Muralidharan, S.; Mirzaei, M.; Mariani, M.; Assadourian, G.; Lee, A.; van Sluyter, S.C.; Haynes, P.A. Less label, more free: Approaches in label-free quantitative mass spectrometry. Proteomics 2011, 11, 535-553. [CrossRef]

68. Krasny, L.; Bland, P.; Kogata, N.; Wai, P.; Howard, B.A.; Natrajan, R.C.; Huang, P.H. SWATH mass spectrometry as a tool for quantitative profiling of the matrisome. J. Proteom. 2018, 189, 11-22. [CrossRef]

69. Schmidlin, T.; Garrigues, L.; Lane, C.S.; Mulder, T.C.; van Doorn, S.; Post, H.; de Graaf, E.L.; Lemeer, S.; Heck, A.J.; Altelaar, A.F. Assessment of SRM, MRM(3), and DIA for the targeted analysis of phosphorylation dynamics in non-small cell lung cancer. Proteomics 2016, 16, 2193-2205. [CrossRef]

70. Saraswathy, N.; Ramalingam, P. Introduction to Proteomics; Woodhead Publishing Series in Biomaterials; Woodhead Publishing: Cambridge, UK, 2011; pp. 147-158.

71. Emwas, A.H.; Roy, R.; McKay, R.T.; Tenori, L.; Saccenti, E.; Gowda, G.A.N.; Raftery, D.; Alahmari, F.; Jaremko, L.; Jaremko, M.; et al. NMR Spectroscopy for Metabolomics Research. Metabolites 2019, 9, 123. [CrossRef]

72. Filimoniuk, A.; Daniluk, U.; Samczuk, P.; Wasilewska, N.; Jakimiec, P.; Kucharska, M.; Lebensztejn, D.M.; Ciborowski, M. Metabolomic profiling in children with inflammatory bowel disease. Adv. Med Sci. 2020, 65, 65-70. [CrossRef]

73. Broadhurst, D.; Goodacre, R.; Reinke, S.N.; Kuligowski, J.; Wilson, I.D.; Lewis, M.R.; Dunn, W.B. Guidelines and considerations for the use of system suitability and quality control samples in mass spectrometry assays applied in untargeted clinical metabolomic studies. Metabolomics 2018, 14, 72. [CrossRef] [PubMed]

74. Mihalik, S.J.; Michaliszyn, S.F.; de las Heras, J.; Bacha, F.; Lee, S.; Chace, D.H.; DeJesus, V.R.; Vockley, J.; Arslanian, S.A. Metabolomic profiling of fatty acid and amino acid metabolism in youth with obesity and type 2 diabetes: Evidence for enhanced mitochondrial oxidation. Diabetes Care 2012, 35, 605-611. [CrossRef] [PubMed]

75. Bian, Q.; Wang, W.; Wang, N.; Peng, Y.; Ma, W.; Dai, R. Quantification of Arachidonic Acid and Its Metabolites in Rat Tissues by UHPLC-MS/MS: Application for the Identification of Potential Biomarkers of Benign Prostatic Hyperplasia. PLoS ONE 2016, 11, e0166777. [CrossRef] [PubMed]

76. Salek, R.M.; Steinbeck, C.; Viant, M.R.; Goodacre, R.; Dunn, W.B. The role of reporting standards for metabolite annotation and identification in metabolomic studies. GigaScience 2013, 2. [CrossRef]

Publisher's Note: MDPI stays neutral with regard to jurisdictional claims in published maps and institutional affiliations.

(C) 2020 by the authors. Licensee MDPI, Basel, Switzerland. This article is an open access article distributed under the terms and conditions of the Creative Commons Attribution (CC BY) license (http://creativecommons.org/licenses/by/4.0/). 